\title{
Brinquedo e brincadeira na educação infantil japonesa: Proposta curricular dos anos 90
}

Tizuko Morchida Kishimoto*

\begin{abstract}
RESUMO: A política educacional do Japão dos anos 90 , influenciada pela globalização e internacionalização, reforma os jardinsde-infância oficiais. Destinada a crianças de 3 a 5 anos, os jardinsde-infância oficiais definem uma proposta pedagógica em torno do brincar, como forma de levar a criança a conhecer seu ambiente, a socializar-se, a aprender a linguagem, a expressar-se e a criar. Em virtude da predominância do atendimento particular no campo da educação infantil e a pouca participação do governo, o brincar ocupa pouco espaço nas escolas infantis.
\end{abstract}

Palavras-chave: Brinquedos, brincadeira, educação japonesa, cultura japonesa

O Japão, à semelhança de outros países, sofre profundas alterações em face da globalização e da internacionalização, discute valores e reforma o sistema escolar procurando ajustá-lo aos novos tempos. O caminho adotado nesse processo teria privilegiado a escolarização ou a socialização?

Os sistemas de ensino, na atualidade, dividem-se em propostas propedêuticas, preparatórias para a escolaridade posterior, com ênfase em conteúdos e centradas na figura do professor e nas orientações voltadas para a socialização da criança em desenvolvimento, em que a brincadeira permite a liberdade de ação, expressão e criatividade.

\footnotetext{
Professora titular e vice-diretora da Faculdade de Educação da Universidade de São Paulo; coordenadora do Laboratório de Brinquedos e Materiais Pedagógicos; docente dos cursos de pós-graduação e especialização em educação pré-escolar.
} 
O alto índice de escolarização alcançado pelo sistema de ensino japonês privilegia conteúdos e competitividade. Entretanto, na esfera pré-escolar, não obrigatória, os jardins-de-infância definem, a partir dos anos 90 , orientações curriculares em que se destaca o brincar. A necessidade de estimular a individualidade, a expressão e a criatividade para equacionar problemas de uma sociedade homogênea e coletivista parece ter levado à opção pelo brincar enquanto ação livre, iniciada e mantida pela criança. Pode-se aventar a hipótese de que há, também, outros elementos de natureza cultural, que poderiam interferir na materialização desse projeto.

Foram investigadas a presença do brincar enquanto política pública de educação infantil, sua manifestação na prática pedagógica e as razões aventadas por profissionais e pesquisadores.

A metodologia de pesquisa privilegiou a análise etnográfica, com gravações em vídeo, complementada com entrevistas semi-estruturadas e análise de documentos oficiais.

As observações realizadas durante três meses, no período de dezembro de 1995 a fevereiro de 1996, tiveram como sujeitos, crianças, especialmente entre 3 e 5 anos e foram realizadas durante dois dias (período de quatro horas), em cada uma das seis instituições de educação infantil. ${ }^{1}$ As entrevistas incluíram dois professores de cada escola, diretores, quatro professores de diferentes universidades que atuam no campo da educação infantil, ${ }^{2}$ membros do setor de educação infantil do Ministério de Educação e Cultura.

\section{Proposta curricular para os jardins-de-infância}

A educação infantil japonesa, à semelhança da de muitos países, não dispõe de um projeto integrado, ao separar creches junto ao Ministério de Saúde e Bem-Estar Social e jardins-de-infância, ao Ministério de Educação. O Quadro 1 demonstra o percentual de atendimento nas duas instituições. ${ }^{3}$

A oferta de unidades infantis junto aos organismos educacionais é alta na faixa de 4 a 5 anos, chegando a $92 \%$ para os de 5 anos, e $86 \%$, para os de 4. Há um esforço governamental para ampliar as de 3 anos que ficam no patamar de $58 \%$. As creches não recebem estímulo para 
sua ampliação, mantendo-se no patamar de $30 \%$, em virtude da tradição de a mulher japonesa dedicar-se aos afazeres domésticos e aos cuidados com a prole. O mercado de trabalho não absorve a mulher, especialmente após o casamento.

Quadro 1 - Atendimento infantil ${ }^{*}$

\begin{tabular}{|l|l|l|l|}
\hline & 3 anos & 4 anos & 5 anos \\
\hline Jardim-de-infância & $28,1 \%$ & $56,7 \%$ & $63 \%$ \\
\hline Creche & $30 \%$ & $30 \%$ & $29 \%$ \\
\hline Total & $58,1 \%$ & $86,7 \%$ & $92 \%$ \\
\hline
\end{tabular}

* Dados fornecidos pelo Mombusho (Ministério de Educação), fevereiro de 1996.

Os jardins-de-infância atendem cerca de dois milhões de crianças e as creches, 1,7 milhão (Education in Japan 1994, p.120).

Os jardins-de-infância oferecem cursos com a duração de um a três anos, a crianças na faixa etária de 3 a 5 anos, em estabelecimentos privados, nacionais e municipais. Há cerca de 49 universidades nacionais, destinadas à formação de professores, com cursos anexos de jardim-de-infância. Em 1992, haviam cerca de 0,3\% de escolas mantidas pelo governo nacional, $41,5 \%$, pela municipalidade e $58,2 \%$, pela iniciativa privada. Entretanto, computado o número de alunos atendidos, apenas $20,4 \%$ das crianças freqüentam escolas públicas e $79,6 \%$, a particular (Education in Japan 1994, p. 22). As instituições privadas não dependem, à semelhança das municipais, da supervisão oficial de propostas pedagógicas, apenas a instâncias estaduais e federais quanto à expansão e à administração. Em decorrência, as orientações curriculares oficiais pouca influência exercem na esfera particular.

O novo plano curricular do Jardim, implementado em 1990, estabeleceu uma educação pelo ambiente, priorizando atividades segundo as características de desenvolvimento da criança, tendo o brincar como um de seus eixos.

O brincar sempre esteve presente na educação infantil japonesa desde a instalação do primeiro jardim-de-infância público em 1876, em Tóquio, junto à Escola Normal para Mulheres. Segundo a profes- 
sora Nezu, da Universidade Gakugei Daigaku, por muito tempo acreditou-se que bastava divulgar a relevância da brincadeira que os professores saberiam adequar o ambiente de aprendizagem. Mas, especialmente a partir dos anos 70 , com a penetração de idéias ecológicas, percebeu-se a profunda influência do ambiente na forma de pensar das pessoas. Vygotsky já apontava nos anos 30: objetos materiais e a cultura de cada povo influenciam a forma de pensar dos seres humanos.

As discussões envolvendo o petróleo e a escassez dos produtos naturais, o modo de vida dos hippies buscando um retorno aos tempos passados fazem o movimento ecológico crescer e despertam a consciência de que o ambiente, a mentalidade e os objetos são fundamentais na educação do homem. Especialmente no caso da criança que ainda não domina a linguagem, a influência do mundo material, natural e humano é decisiva. A partir de então, os guias curriculares preconizam a educação pela brincadeira em seu ambiente.

A nova proposta do brincar parte da concepção holística da criança, inserida em contexto educativo, que integra cinco áreas curriculares: saúde, relações humanas, ambiente, linguagem e expressão. Tais áreas não visam à estruturação de atividades, à semelhança da escolarização, mas indicam que a criança, ao brincar, desenvolve, ao mesmo tempo, a saúde, socializa-se por meio de interações com os pares, explora o ambiente que a rodeia, expressa seus pensamentos e cria formas próprias de expressão.

A política pública de educação infantil vem, desde 1990, destacando o brincar: "Atingir as metas da educação por meio de uma educação pelo brinquedo" (Japanese Government Policies in Education, Science and Culture 1994, p. 56).

Embora brinquedos e brincadeiras já fossem prática na educação infantil japonesa, é a primeira vez que aparecem como eixo desse nível de ensino.

"Education's guideline for Japanese kindergarten", ${ }^{4}$ publicado pelo Ministério de Educação e Cultura, em sua versão de 1994, destaca o brincar em vários pontos:

Manutenção da saúde mental e corporal: "Controlar e mover seu corpo por meio de várias brincadeiras. Ter prazer e realizar várias atividades externas" (p. 5). 
No campo das relações humanas o desenvolvimento de autonomia e socialização aflora o lúdico: "Compreender o prazer de brincar e trabalhar junto com os colegas." "Ter cuidado no uso de brinquedos da classe e coisas feitas pelos outros" (p. 7).

Ao permitir a ação independente com parceiros, o brincar fundamenta o desenvolvimento de relações humanas.

A área curricular de Ambiente considera que a criança deve desenvolver habilidades para interagir positivamente com seu meio natural e social e incorporá-lo em sua vida diária com os objetivos de: "Ter prazer em experimentar fenômenos e eventos da natureza por meio de brincadeiras; brincar pela experimentação e criar com coisas que a cercam; desenvolver interesse por brinquedos e coisas feitas pelo homem" (p. 8).

$\mathrm{Na}$ área da linguagem, pretende-se que a criança relate experiências e se expresse por palavras do cotidiano, aprenda a ouvir os outros e desenvolva a compreensão da linguagem. As situações que favorecem o uso de símbolos como o faz-de-conta são facilitadoras para o aparecimento da linguagem e relacionam-se com a expressão do imaginário infantil: "Expressar a imaginação por meio da linguagem, movimentos corporais e faz-de-conta" (p. 12).

A área de Expressão visa, por meio do ambiente, desenvolver a criatividade e a expressão. O conteúdo do currículo prevê a ação livre da criança e enfatiza o lúdico:

Ser livre e expressar criativamente sentimentos e idéias pelo uso de sons, movimentos corporais, desenhos e produzir coisas feitas com as mãos.

Usar vários materiais para criar outras coisas.

Ter contato prazeroso com a música e cantos em grupos a partir de instrumentos simples.

Ter prazer no desenho e trabalhos manuais e usá-los para autoexpressão e brincadeiras (p. 12)

A opção pela socialização e a distância da escolarização que alfabetiza aparecem no item Considerações: "Ao ensinar linguagem para a criança neste estágio, não é aconselhável ensinar letras ainda porque este conteúdo deve ser ensinado na escola elementar" (p. 11). 
A proposta, ao enfatizar valores como o desenvolvimento integral, a auto-responsabilidade, a cooperação, a moralidade, a inserção da criança no mundo natural e social, o desenvolvimento da linguagem, a criatividade, o senso estético e a expressão de sentimentos, ${ }^{5}$ aproxima-se de objetivos sugeridos por sistemas infantis de muitos países. Entretanto, há fatores culturais que conferem colorido especial a cada um desses valores. Diversos estudos (Hendry 1986a/b; Shields Jr. 1993; Finkelstein, Imamura, Tobin 1991; Peak 1991, Tobin et al. 1987) mostram a preponderância das características coletivistas da sociedade japonesa e seus reflexos no sistema escolar. A inserção da criança no grupo como objetivo prioritário da educação infantil japonesa é apontada na pesquisa de Tobin et al. (1987), realizada nos anos 80, que identifica diferenças culturais entre Japão, China e Estados Unidos. O Quadro 2 reproduz as escolhas feitas por 720 professores entrevistados nos países envolvidos.

Quadro 2 - Objetivos da educação infantil*

Qual a razão mais importante para a sociedade criar e manter pré-escolas?

\begin{tabular}{|l|c|c|c|}
\hline Itens & Japão & China & EUA \\
\hline Dar à criança condições de ser membro de um grupo & 61,4 & 12,3 & 19 \\
\hline Dar a oportunidade de brincar com outras crianças & 13,9 & 8 & 14 \\
\hline Dar à criança bom início acadêmico & 3 & 37,3 & 20,5 \\
\hline Tornar a criança mais independente e autoconfiante & 13,6 & 10,6 & 21 \\
\hline Tirar a criança da rua e torná-la boa cidadã & 5,4 & 11,4 & 3,5 \\
\hline Liberar pais para o trabalho e outros afazeres & 1,4 & 16,5 & 6,5 \\
\hline Outras razões & 5,0 & 3,9 & 15,5 \\
\hline
\end{tabular}

${ }^{*}$ Fonte: Tobin et al. (1987, p. 543)

No quadro, 61,4\% de japoneses valorizam "ser membro do grupo", enquanto $21 \%$ de americanos, "tornar-se independente e autoconfiante" e $37,3 \%$ de chineses, o "resultado acadêmico". São tais orientações que diferenciam a pré-escola de cada país.

A inserção da criança no grupo, como objetivo prioritário da educação japonesa, pode ser vista, também, nas entrevistas dos professores. Para Chie Okubo, administradora da creche de Osaka, 


\begin{abstract}
a tarefa da pré-escola é produzir ninguen-rashii kodomo (criança como ser humano). Para tornar-se ser humano completo não basta ser um indivíduo, é preciso ser membro de um grupo. Do que tenho visto nas escolas americanas percebo como eles fizeram um bonito trabalho ao tornar a criança criativa, autoconfiante e dotada de individualidade. Nós acreditamos que mais importante é que a criança aprenda a viver como membro de um grupo.(...) Mas você vê, isso não é só problema de pré-escola: é um problema de toda a sociedade porque o grupismo é estimulado não só nas pré-escolas mas também em nossas escolas primárias, secundárias e universidades, nos negócios e assim por diante. Eu penso que essa é a diferença básica entre os japoneses e as culturas estrangeiras. Nós, japoneses, somos um povo com orientação grupal; dessa forma, é natural que nossas pré-escolas o sejam. (Tobin et al. 1987, p. 544)
\end{abstract}

Os objetivos da educação infantil expressam valores cultivados e reproduzidos pela escola e pela sociedade, o que é confirmado por Kumagai, assistente da diretora do jardim-de-infância Senzan:

Professores em nosso yotien têm 30 crianças para olhar e isso não é uma coisa ruim porque força a criança a aprender a lidar com o problema e as discordâncias de outros. Elas podem ter a atenção individualizada de suas mães. É bom, para elas, ter a experiência de interagir com outras crianças sem suas mães por perto. (Tobin et al. 1989, p. 540)

Cooperação, respeito pelo grupo, cordialidade são valores inerentes aos japoneses e fazem parte de sua cultura.

A consciência de grupo é um traço cultural antigo proveniente do período Tokugawa - 1615-1867 - , que integra as fontes contemporâneas da cultura japonesa. A competição no plano individual surge, no período Meiji (1867), quando foi abolido o sistema de clãs hereditários dos samurais e estabeleceu-se o capitalismo.

Pela forte consciência de grupo, as condutas coletivas sobrepujam as individuais, tornando difícil ao povo japonês aceitar outras visões de mundo (Kato 1987, pp. 86-90). É comum o uso de roupas iguais e o ritual de beber saquê após o expediente, na companhia dos colegas de trabalho. 
A orientação para a inserção grupal continua presente no currículo atual e na prática docente. Professores de educação infantil atribuem responsabilidade às crianças em muitas atividades: elaborar regras, resolver conflitos e problemas. É ainda a valorização do grupo que explica a prática do agrupamento para diferentes tarefas (kumi). Cada kumi elege seu líder, em eventos atléticos, nas tarefas acadêmicas e de organização da sala. Dentro de cada kumi existem os hans, subdivisões do agrupamento com tarefas específicas como cuidar dos animais, responsabilizar-se pela chamada das crianças na hora do katazuke (arrumação).

A valorização do coletivo parece estar relacionada à nostalgia dos tempos de inserção da criança na grande família. Hoje, a família nuclear, com poucos filhos, parece conduzir à estratégia de classes numerosas como forma de combater o que os japoneses entendem ser o espírito individualista da conduta ocidental. Divergindo de padrões americanos e europeus, que propõem critérios de qualidade baseados na relação entre adulto e criança, os japoneses consideram a interação da criança em grandes agrupamentos como a forma adequada para o desenvolvimento infantil. Apreciam atitudes como deixar o pré-escolar ser criança, fazer barulho, criando um ambiente propício para que aprenda a viver em grupo, especialmente em classes numerosas.

Professor Ogawa, em janeiro de 1996, dizia ao diretor do Tawara Yootien: "É uma pena que a escola tenha apenas 15 alunos na classe. É preciso fazer algo para aumentar." Perguntei por que esse número era considerado inadequado, uma vez que se tratava de crianças de 4 anos. Sua resposta aponta para a diferença entre a educação familiar e a institucional: as crianças vivem sozinhas com suas mães em casa, interagem na díade mãe-criança, prevalecendo o atendimento individualizado. No jardim-de-infância, prioriza-se o grupo, a coletividade. Assim, a escola propicia a passagem da vida familiar à vida, permitindo que a criança, que já teve atenção individualizada no lar, complemente com a educação grupal. No entender do professor, quando há poucas crianças, predomina a tendência de andar juntas e fazer sempre as mesmas coisas, impedindo a manifestação da individualidade e da independência. Os jardins públicos atendem 35 crianças, de 4 a 5 anos, e 20, de 3 anos, número considerado ideal. Os parâmetros estabelecidos por organizações americanas e européias, de 12 a 20 crianças para as idades de 4 e 5 anos, não são considerados adequados pelos japoneses. Entendese que, para brincadeiras coletivas, requer-se um contingente maior de crianças. 
A cooperação e a inserção da criança no grupo são valores a ser buscados no ambiente físico e nas práticas pedagógicas.

A cooperação é estimulada a todo momento pela disposição e pelo tipo de materiais disponíveis nas salas. O katazuke (arrumação) da sala, na hora do lanche, exige a participação de todos: a mesa com dobradiça requer o auxílio de quatro crianças para desdobrá-la; mesas e cadeiras encostadas na parede precisam ser armadas; as crianças que assumem papéis de tobam (plantão) transportam o bule de chá para servir a seus colegas. Nas horas de brincadeiras: blocos e tábuas grandes de madeira exigem parceria para seu transporte. Projetos coletivos são estimulados a todo momento: diversos grupos envolvem-se na organização de hanaya (floricultura), sushiya (casa que vende bolinho de arroz, sushi), mandiuya (casa que vende bolinho de feijão, mandiu). Tais atividades conjuntas ocorrem em um ambiente que propicia a cooperação e exige o cumprimento das normas definidas pelos próprios pares e não pelo professor. Ao colocar materiais para uso coletivo, pretende-se que a criança aprenda a pedir emprestado e, dessa forma, prepare-se para a cooperação.

Um representante do Ministério de Educação e Cultura, da área de Educação Infantil, relata o caso de um garoto que, em vez de realizar seu projeto individualmente, esperou pacientemente o momento adequado para ter a companhia dos colegas. ${ }^{6}$ Fato considerado exemplar para demonstrar a relevância e o prazer advindos do trabalho conjunto com parceiros.

A valorização do trabalho grupal funciona como guia para orientar a conduta do professor. Ao distribuir atividades ao longo da rotina escolar, o professor chama as crianças por grupo: o que brincou de faz-deconta, o que fez construção, o que brincou na areia, o que brincou de super-heróis. Embora exista preocupação com a expressão individual, a cooperação em grupo a sobrepuja. Há casos de conflito entre os interesses individuais e grupais. Observei uma garota de 5 anos dizer que, após um dia de atividade, não queria continuar seu projeto de fazer uma floricultura com seu grupo inicial. Houve uma série de discussões entre a professora e a menina, em que se perguntava: Como fica o grupo? O jardim-de-infância, considerado um período de passagem, de adaptação da criança, egocêntrica, não-socializada, para uma etapa de socialização e cooperação, não requer o cumprimento rigoroso dessa conduta, como na escola primária.

Segundo Lewis (1993, p. 35), para os japoneses, a internalização das normas se processa através de quatro estratégias: 
1. Minimizar o controle do professor;

2. Delegar o controle à criança;

3. Oferecer plenas oportunidades para a criança adquirir identidades positivas; e

4. Levar a criança à compreensão e à socialização para evitar condutas errôneas.

A internalização das normas na sociedade japonesa ocorre de forma muito mais forte que nas ocidentais. Comentei, com o professor Ogawa, as observações que efetuei no Brasil, em 1994, em escolas infantis: as crianças japonesas de 4 a 5 anos cumprem com maior rigor as normas das brincadeiras que as brasileiras. Para o professor, isso se deve a questões culturais, de reprodução de condutas da sociedade japonesa, da compreensão de que as regras devem ser cumpridas: os trens chegam e partem no horário estipulado, o horário é rigorosamente cumprido em todos os lugares: na família, no comércio, na indústria, na escola e na sociedade em geral. A imersão em uma cultura em que o cumprimento da norma faz parte do cotidiano permite fácil interiorização desse valor. Na sociedade brasileira, as normas são sistematicamente violadas. Não se respeitam os sinais de trânsito, o horário de chegada e saída da escola; compromissos são violados a todo instante. Tais atitudes aparecem nas brincadeiras, com o sistemático violar das regras. No Japão, se a norma diz que a brincadeira deve terminar quando chega a hora do katazuke, rapidamente as crianças começam a arrumar o espaço.

A nova reforma pretende estimular a expressão da individualidade e da criatividade, aliada à inserção da criança no grupo. Kaminaga ${ }^{7}$ aponta o dikohaki ( realização de projeto) como objetivo importante a ser buscado nos jardins-de-infância. Materializar projetos e idéias, envolvendo parceiros, mostra o nível de desenvolvimento e a capacidade de a criança relacionar-se com outros. Cultivar a individualidade sem deixar de inserir a criança na sociedade parece ser o desafio da educação japonesa dos tempos atuais.

Garantir a expressão individual dentro de uma sociedade cooperativa, meta da educação infantil japonesa, parece encontrar obstáculos, pela falta de continuidade política. Nos níveis de escolaridade subseqüentes à educação infantil, predomina a orientação grupal em detrimento da individual. Expressar sentimentos, desenvolver uma forma pessoal de vestir, falar e pensar são vistos como "ser diferente", o que é, ain- 
da, bastante difícil de ser aceito. Os japoneses temem ser discriminados ao expressar condutas não-usuais. Porém, essa atitude ainda não é adotada no período da educação infantil porque as crianças são consideradas não-socializadas, em fase de passagem, portanto, não devem ser cobradas por esse comportamento. Ser socializado significa ser igual, expressar pensamentos culturalmente aceitos. A socialização requer 0 aval do grupo. Se a conduta é compatível com interesses do grupo, é tida como socializada. Caso contrário, é ser diferente. Ouve-se constantemente: Nani, dibum no koto dake kangaeru! (Ora, só pensa em seus interesses!).

A cooperação e o trabalho em grupo são traços culturais da sociedade japonesa presentes na educação infantil, na organização do espaço físico e na conduta das pessoas que são avaliadas por tais critérios.

\title{
Prática pedagógica e a visão de professores \\ e diretores sobre o brincar
}

Para a professora da turma de 3 anos do jardim-de-infância particular Futaba Yootien de Toyohashi, Aichi-ken,

\begin{abstract}
o brincar livre é importante para a criança de 3 anos iniciar a socialização, a cooperação e a independência. Pelo brincar a criança se atreve a fazer amizades, inicia o processo de cooperação nas situações de brincadeiras. Somente a brincadeira livre permite a ação independente da criança.
\end{abstract}

A professora Yamada, da classe de 5 anos, complementa: "Brincar é importante quando é livre porque a criança expressa seus sentimentos, sua individualidade". Para Abe, diretor da escola, "brincar é importante para a criança aprender, por exemplo, no faz-de-conta, a assumir papéis e compreender as relações de trabalho, cooperação, relações sociais necessárias para sua inserção social".

O processo que vai da expressão individual à inserção grupal é explicado pela professora da turma de 3 anos: "No início, a criança interage com objetos, espaços e manifesta sozo (expressão individual). Gradativamente, essa interação integra relações com outras crianças, 
fala, trocas, disputas. A ação livre permite que aprenda a expressar seus desejos em ações concretas, em projetos coletivos, tornar-se shakaiseki" (membro de grupo)."

Considera-se importante deixar a criança agir com pouca interferência do adulto. Conforme o professor Ogawa, a auto-educação possibilita à criança desenvolver a capacidade de fazer seu plano para brincar. Ao professor cabe a função de organizar o kamkiou (ambiente), considerado fundamental para o aparecimento da brincadeira.

Observar a criança para compreender seus projetos, ficar disponível para auxiliá-la na materialização de suas idéias são tarefas importantes do professor. As crianças do jardim-de-infância anexo à Universidade Gakugei Daigaku circulavam pela escola toda e os professores ficavam, geralmente, nos mesmos lugares, observando e dando apoio.

Há preocupações com o novo modo de vida consumista da sociedade japonesa. Segundo a diretora do jardim-de-infância particular de Toyohashi (Nagoya), a tendência das mães é comprar tudo pronto. Dessa forma, as crianças têm poucas oportunidades de aprender processos simples de fabricação de objetos e alimentos. A escola, em situações de brincadeira, ensina a criança a secar o caqui, a preparar comidas simples, a fabricar objetos e procura levar as mães a repetir a brincadeira em casa. Com o entusiasmo das crianças, as mães acabam se envolvendo e procuram a escola para entender o processo de fabricação para assessorar os filhos.

O gosto pela leitura é estimulado desde cedo em todas as instituições infantis, sempre muito equipadas com diferentes tipos de livros. A biblioteca da escola, com cerca de cinco mil volumes destinados a crianças e pais, e uma videoteca podem ser utilizadas, três vezes por semana, podendo emprestar cerca de seis livros por semana (três para a criança e três para os pais). É interessante observar como as crianças, em contato freqüente com a leitura e a escrita, acabam lendo e escrevendo, por meio de brincadeiras, sem que exista um projeto para alfabetizálas nessa fase. As crianças que freqüentam a biblioteca preenchem as fichas dos livros que estão lendo e, quando não sabem escrever, recebem auxílio da bibliotecária e de parceiros. Os livros fazem parte do cotidiano do Jardim. Há livros com desenhos de processos de fabricação de objetos, de seres da natureza e do mundo cultural. A criança que quer fazer algo diferente, procura no livro idéias para seu projeto. Observei crianças que olhavam um livro sobre astros e estrelas para fabricar objetos para seu canto de filmes. Acabaram fabricando astros com papel 
laminado, colocando tiras nas bolas à semelhança dos anéis de Saturno. Outra olhava um livro para preparar, com argila, flores para seu projeto de floricultura. Outra folheava livros com desenhos de comidas e fazia sushis para materializar seu sushi-ya (casa que vende sushis). Crianças de 4 anos, no Jardim da Gakugei Daigaku, usavam carimbos de letras e outras figuras para se divertir aproximando-se da escrita. As que fabricavam objetos para vender faziam cartazes e, com pouca ajuda dos professores, acabavam escrevendo os letreiros para suas lojas.

Nas brincadeiras de fabricação de objetos para vender, ouvia-se o professor sempre dizer sutequi (bonito), oishissona (parece gostoso) ou gambare (esforço). A criança envolvia-se no processo de produção conforme seu interesse e, a cada dia, a brincadeira crescia, prolongando-se por semanas: primeiro no papel de fabricante (flores, comidas, objetos), depois, no de vendedor. Armavam-se barracas, faziam-se saquinhos ou cestas para embalar os produtos, cartazes para identificar as barracas. Em seguida, convidavam as turmas de 3 anos para vir fazer compras. Outras crianças preparavam peças de teatro, com figuras recortadas em papelão e que se movimentavam por meio de pedaços de ímã. Contavam histórias lendo livros e movimentando peças diante de um teatro improvisado (um pedaço de pano colado em uma divisória). Preparavam o espaço, incluindo fundo musical e trazendo cadeiras. Anunciavam o início da peça, com todos os detalhes como fazem os adultos. São impressionantes o nível de desenvolvimento verbal dessas crianças de 4 anos e a espontaneidade com que conduzem as situações. Os professores procuram não interferir e as crianças organizam tudo. Preparam o ambiente, a peça, chamam os convidados e, mesmo quando algo sai errado, como personagens de papelão que caem diante do público, pela movimentação inadequada das peças, os professores não intervêm. As crianças pedem desculpas e refazem o cenário.

Crianças de 3 anos, convidadas a comprar objetos produzidos pelas maiores, confeccionam bolsas com dinheiro e saem às compras. $O$ cuidado com a produção das embalagens reflete o valor da estética como tradição cultural, cultivada desde cedo. Há o cuidado por parte de crianças de 5 anos no preparo de saquinhos ou cestas para embalar flores ou comidas, procurando sempre pregar algum enfeite para dar o acabamento.

As brincadeiras também incorporam as tradições do país. No dia 3 de fevereiro comemora-se a mudança de estação espantando os demônios com feijões, brincadeira conhecida como mame-maqui. As crianças preparam no dia anterior os demônios e as cestinhas para colocar 
feijões. Algumas fazem feijões com papéis picados. Os menores de 3 anos pintam um demônio feito com caixas de embalagens, confeccionam cestinhas com dobraduras e picam papéis. As festas populares, com rituais de agradecimento aos deuses pela vida saudável das crianças de 3 a 5 anos, recebem atenção especial. Os professores comparecem à escola mesmo sendo feriado, para receber pais e crianças vestidas com kimonos e roupas especiais, cumprimentá-las e a seus pais, que se dirigem aos templos para agradecer e pedir às divindades saúde para os filhos. A integração entre família, escola e tradições culturais é bastante forte. Para preservar brincadeiras tradicionais, ensinam-se processos de fabrico de brinquedos e brincadeiras dos tempos passados, estimulando os pais a brincar com os filhos.

\section{0 ambiente físico da escola}

A ampla sala, contendo materiais para organizar cantos de faz-deconta, construção, oficinas de produção de objetos, difere das salas dos Jardins brasileiros lotadas de mesas e cadeiras. As mesas, dobráveis, encostadas na parede, são armadas, quando se necessita, ou na hora das refeições. As cadeirinhas ficam empilhadas. Quando se requer uma mesa, para a realização de oficina, quatro crianças vão armá-la. Por ser pesada, com dobradiça, requer esforço coletivo, o que estimula a cooperação. Se a mesa já estivesse disponível, não haveria necessidade do esforço coletivo para prepará-la. Para terminar os preparativos para a oficina, coloca-se um plástico para a proteção da mesa e aproxima-se uma estante, com rodinhas, contendo materiais (papéis, tesoura, fitas adesivas de todas as cores, canetas coloridas): está preparado pelas próprias crianças o canto para início do projeto.

As crianças dispõem de salas próprias conforme a faixa etária, mas desenvolvem atividades heterogêneas, conforme interesses próprios, com total liberdade de circulação: uma criança faz uma espada com papéis enrolados, outra, um carrinho com caixas de leite, as meninas fazem flores e outros objetos. É freqüente a formação de grupos de crianças envolvidas em projeto comum. A alegria de brincar é uma constante. Observamos uma criança que fazia um robô, com caixa e papel laminado e um garoto resolveu ajudá-la. Quando a professora comentou que o robô estava sutequi (bonito), o menino vibrou de alegria, compartilhando o prazer da produção. Muitas vezes, as crianças observam as 
brincadeiras de outros colegas. Deixam seus projetos, mas retornam depois. Brincar de super-heróis, fazendo espadas com papel enrolado e colado com fita adesiva parece a brincadeira preferida dos meninos.

Um grupo de meninos usa blocos de construção para fazer um ônibus. Eles dividem uma área com blocos e colocam cadeirinhas como assentos de passageiros. $O$ volante do motorista e as placas de papelão coladas com fita adesiva dão o contorno do veículo. Outro grupo faz um canto para passar filmes. Com a ajuda do professor, eles colam tiras de panos, isolam um canto com blocos de construção, fazem uma cortina que o professor fixa no teto. Um retroprojetor colocado no interior do improvisado cinema ilumina configurações com papéis furados parecendo estrelas e astros.

As meninas se envolvem em atividades de confecção de objetos ou faz-de-conta. Deitam em pequenos futons (acolchoados usados como camas) e ficam conversando.

Há caixas contendo trilhos e trens para armar ferrovias. Essa era a atividade preferida por um deficiente físico, de 4 anos, com dificuldade para andar.

Geralmente, os Jardins possuem um amplo salão, para múltiplos usos, que, no cotidiano, serve como espaço para brincadeiras livres e, especialmente, de construção, com blocos maiores, congregando os dois sexos. Os meninos organizam seu espaço de aventura com escorregadores, criam lugares para esconder, e subir; as meninas fazem casinhas, com blocos de construção e enfileiram apetrechos de cozinha para o faz-de-conta.

A disposição e a identificação de equipamentos e materiais facilitam a auto-organização da criança que não precisa esperar o professor distribuir materiais para iniciar a brincadeira. A criança mal chega à classe já corre para um canto ou vai para o amplo espaço externo na companhia de algum colega.

Os professores só são requisitados quando falta algum material ou a criança não consegue dar conta de seu projeto, ou quando há confrontos físicos entre crianças gerados pela destruição involuntária de brinquedos. São poucos os casos de brigas por materiais, uma vez que se estimula a cooperação e sempre há quantidade suficiente deles.

A organização da classe é facilitada pela disposição dos materiais, mas também pelo sistema de tobam (pessoas responsáveis por certas tarefas). Geralmente, as crianças arrumam pelo menos o espaço em 
que brincaram, as meninas mais que os meninos. Parece ser um dado cultural a atividade doméstica feminina. ${ }^{8}$ Há, também, respeito pelo horário. Quando se anuncia que terminou a hora da brincadeira e chegou a do katazuque, ouvem-se crianças dizendo: "Puxa, agora que começamos a brincar, já chegou a hora." Alguns continuam seus projetos, enquanto a maioria inicia a arrumação. É comum ouvir: "Amanhã vamos gambaru de novo", e iniciam, em parceria, a demolição da imensa estrutura que construíram, levando as peças para os seus lugares. Em meia hora arrumam os espaços, aprontando as mesas e cadeiras para a próxima atividade: refeição, cantar, ouvir história, roda de conversas.

Após a saída das crianças, os professores permanecem por mais algumas horas (três a cinco) para organizar o ambiente, preparar os materiais para o dia seguinte ou participar de reunião.

Não foram localizados brinquedos de encaixe, classificação, jogos de tabuleiro, que impliquem regras lógicas, como trilhas, percursos, à semelhança do modelo brasileiro. Há predomínio de materiais que favorecem manipulação, construção e atividades coletivas. Certamente os brinquedos educativos são utilizados pelas famílias, em suas interações com os filhos.

Traço cultural marcante é a paciência do professor no horário do katazuke. Não se altera, mesmo quando as crianças continuam a brincar ou então, após haver sido devidamente arrumado, algumas voltam a brincar e a tirar tudo do lugar fazendo, de novo, os cantos de brincadeiras. Geralmente, professores da turma de menores de 3 anos têm maior dificuldade para iniciar as crianças na rotina da escola. Pedem ajuda às crianças, sem gritar, e começam a fazer sozinhos a arrumação, até que algumas crianças iniciem o trabalho. As meninas são mais prestativas nesse tipo de atividade. Os meninos continuam a brincar de super-heróis, a rolar pelo chão, enquanto as meninas, com vassouras e pás, começam a retirar o lixo. Só depois de um tempo os outros iniciam a arrumação dos blocos de construção.

Nas seis escolas visitadas, a rotina escolar é marcada pela brincadeira livre. Desde o momento em que chegam à escola até o final do dia, predomina a brincadeira livre, em cantos organizados pelas próprias crianças. A configuração e a disposição de móveis e materiais nas diversas salas e área externa facilitam o brincar livre. As portas das salas estão sempre abertas, permitindo o fluxo contínuo de crianças de 3 a 5 anos que, misturadas, materializam seus projetos, enriquecidos pela 
visualização de diferentes modelos, de adultos e crianças de diferentes idades. Não há atividades homogêneas e padronizadas, exceto em momentos destinados ao ensino de música, dança, conto de histórias. O professor é sempre um facilitador da aprendizagem, ficando em segundo plano, dando suporte para os grupos que o solicitam ou desenvolvendo oficina com outros. Os materiais privilegiam a construção: blocos froebelianos grandes, peças gigantes para montar casinhas, caixas de leite, copinhos, papéis, canetas, tintas, colas, fitas adesivas coloridas, massas, peças de encaixes para construções gigantes, caixas moduláveis, escadas; materiais para brincar na areia: baldes e pás de diferentes tamanhos, água; materiais para atividades motoras: triciclos, bicicletas, argolas, autoramas, escadas, plintos, colchonetes, barras de equilíbrio, escorregador, balança, equipamentos de playground simples e complexos; brincadeiras tradicionais: cordas, pernas-de-pau, pião, raquetes, judô, fazer bonecas e objetos para festas tradicionais como onigoko (malhar o diabo), hinamatsuri (comemoração das bonecas), e brincadeiras simbólicas: tanques de areia, brinquedos para casinhas, plásticos, papel e papelão que se transformam em roupas, divisórias e elementos que materializam projetos infantis.

As crianças engajam-se principalmente em atividades de construção que se transformam em faz-de-conta. Pela construção de uma cabana com tábuas e caixas disponíveis no grande salão entra-se no tema da "casinha": montando e desmontando uma casinha que fica no pátio assumem o papel de marceneiros; as brincadeiras das meninas no tanque de areia desenvolvem o tema de "fazer comida". As crianças fazem espadas com pedaços de jornal, imitam super-heróis, constroem, com papéis coloridos, doces, comidas típicas, flores e armam barracas para vendê-las. O consumismo da sociedade japonesa aparece nas atividades simuladas pelas crianças de produzir bens de consumo (alimentos e produtos para venda). Quando das festas populares, constroem diabos (onis), caixas para acondicionar feijões (mames) para atirar nos diabos e bonecas hinas, com papéis coloridos.

Para o professor Ogawa, o fato de as crianças armarem um canto de faz-de-conta, no Tawara Yootien, em frente da porta, encurta a brincadeira, por ser um local de passagem e muito movimentado. Isso ocorre porque a professora não colocou o material da brincadeira em outro lugar, mais distante da porta. Ao observar outra atividade coletiva de produção de enfeites para festividades da escola, o professor critica o modelo escolar, padronizado, sem possibilidade de opção da criança. A 
mesma atividade adquiria novo formato, privilegiando a heterogeneidade, ações variadas conforme os interesses infantis. Em Akita, grupos de crianças preparavam caixinhas para condicionar feijões (mames) e atirar nos diabos (onis), na festa tradicional de malhação do diabo, enquanto outras ficavam envolvidas em brincadeiras de construção, faz-de-conta e lutas entre super-heróis. As atividades apresentam a mesma finalidade: envolver crianças nas brincadeiras, mas as alternativas metodológicas mostram valores diferentes: ora predominam a direção e a homogeneidade de ações, ora a livre opção, o respeito por interesses e necessidades infantis.

Condena-se a organização da sala, sem uma disposição que auxilie a criança a decidir o que fazer e sem informações visuais para a entrada no imaginário. É bastante comum nas escolas brasileiras o uso de uma caixa com brinquedos misturados, no meio da sala, para "brincadeiras livres". Tal prática estimula a disputa, a briga pela posse do brinquedo, prejudicando a realização da brincadeira simbólica. Pesquisadores canadenses observaram que crianças pequenas, entre 3 e 4 anos, necessitam de cantos organizados, com objetos que permitam o aparecimento de imagens mentais, ainda pouco numerosas, em crianças dessa faixa etária, para que surja a brincadeira de faz-de-conta. Deixar caixas com brinquedos, sem nenhum indício mais concreto que auxilie a criança na definição do tema da brincadeira, parece não ser a atitude mais adequada para estimular o aparecimento do imaginário. Na visão de Ogawa, quando crianças de 4 anos não brincam de faz-de-conta é porque não há um ambiente adequado. Pois o natural dessa idade é usar a modalidade de brincadeira. Para o pesquisador, o Jardim não deve receber uma organização semelhante à sala de aula, pois não tem essa finalidade. Deve ser um espaço de exploração, bastante tranqüilo, onde se saiba o que fazer e com o que fazer. Os locais para guardar os materiais devem estar sempre fixos e com tabuletas para orientar a organização. A criança pequena precisa de regularidade para compreender seu ambiente. Uma sala em que os materiais estão sempre em lugares diferentes não permite à criança explorar autonomamente e não a motiva para explorá-lo.

Ogawa destaca três pontos relevantes na organização do ambiente de aprendizagem: ${ }^{9}$
1. brinquedos e materiais para brincar;
2. espaço ajustado às necessidades da criança; e
3. amigos para interagir. 
O professor deve estar sempre nos lugares conhecidos pela criança, para the dar tranqüilidade.

A gradativa conquista da autonomia trará segurança à criança em suas investidas na exploração de novos espaços, o que supõe ter, no início, o professor à sua disposição.

O desenvolvimento e a aprendizagem da criança por meio da brincadeira ocorrem quando se adquire a rotina do brincar pela presença constante de material, memorização do ambiente e confecção de objetos pela observação de modelos.

Ao analisar a relação espaço e brincadeira, como no esconde-esconde, ou no pega-pega, o professor mostra que o prazer está em se esconder, mas também deixar-se pegar, para ter graça. Se o espaço é grande demais, não se consegue pegar e a brincadeira perde a graça; se é pequeno demais, também não há graça, pois não se pode esconder.

A brincadeira requer observadores. Há prazer em brincar diante de outras crianças. Daí ser necessário que o canto do faz-de-conta não seja totalmente isolado, a criança possa ver o adulto e outros parceiros, caso contrário, perde a graça.

Quando as outras dirigem-se para um lugar distante, a criança tende a deixar de brincar para acompanhar o grupo, o que mostra que um espaço amplo demais não favorece a brincadeira.

Ogawa entende que as opções de brincadeiras infantis dos diversos grupos, propiciadas por um espaço organizado para tal finalidade, servem como modelos iniciais para a entrada no imaginário. Essa cadeia de opções, representa a formação social, a cultura que se oferece às crianças dentro de uma sociedade delimitada em um tempo e espaço.

Outro fator importante para a interação adulto e criança é a altura em que o professor se coloca. Não deve ficar na posição de dar aula, de pé, mas como parceiro, ficar à altura das crianças, sentado no chão ou de bruços.

Avesso à postura espontaneísta, Ogawa critica os que ficam apenas olhando a brincadeira, não interagem para auxiliar a desencadear o processo de brincar.

O professor comenta que, no Japão, a proposta do brincar ainda não foi compreendida pela maioria dos professores, que adotam o modelo acadêmico, de atividades padronizadas. Para ele, as pesquisas são insuficien- 
tes para justificar a relevância do brincar e, em sua grande maioria, os referenciais adotados permanecem no plano de considerações românticas.

\section{Brincadeiras tradicionais}

A modernização do Japão eliminou os espaços públicos destinados às brincadeiras tradicionais infantis e o contato com a natureza. A política educacional implantada em 1970 incluiu nas escolas um acervo de brinquedos tradicionais: corda, perna-de-pau, piões e raquetes, cantos com plantas e animais, peixes e aves. Essa orientação prevalece na maioria das unidades visitadas.

No primeiro dia letivo do jardim-de-infância anexo à Universidade Gakugei Daigaku, o diretor deseja feliz ano-novo às crianças reunidas no salão, falando de brinquedos e brincadeiras tradicionais: "Como no ano passado, ao rodar pião, perdi do professor do Jardim; durante as férias treinei bastante rodar pião, esforcei muito (gambarimashita), portanto, sei que vou ganhar desta vez!" O professor replica: "Como eu ganhei do diretor, não precisei treinar!"

Ambos fazem uma demonstração diante dos alunos rodando piões: o diretor roda bem; o professor falha duas vezes e diz que deve treinar mais. O diretor atribui ao treino seu êxito. Pede para as crianças gambaru (aprender pelo interesse e pelo esforço) e também para que façam bastante renshu (treino). A mesma tática é utilizada pela vice-diretora, ao jogar raquete com uma professora, assinalando que é preciso treinar para manter a habilidade. Piões e raquetes estão sempre disponíveis e os professores se empenham em ensinar a rodar pião e jogar peteca.

Para a diretora de jardim-de-infância anexo à Universidade de Akita, uma das principais preocupações de sua escola é que a criança adquira a cultura local por meio de brincadeiras folclóricas. Piões, cordas, pernas-depau, exposições de bonecas hinas, brincadeiras de preparar comidas típicas como assar o moti (bolinho de arroz) fazem parte do cotidiano escolar.

\section{Gambaru: Currículo oculto que legitima práticas pedagógicas}

É comum entre professores e diretores o uso do termo gambaru para indicar treino e esforço. As crianças comentam: "Amanhã vamos 
'gambaru' no canto de construção". ${ }^{10}$ Tal prática não ocorre apenas no interior da escola mas em todos os campos de atividade, integrando-se na cultura japonesa. Jogadores de futebol ou beisebol dizem que vão "gambaru" para ganhar; assalariados comentam que nesse ano sua firma foi bem-sucedida porque todos se esforçaram (gambarimashita); as mães não se cansam de recomendar aos filhos gambaru nos estudos.

Para Singleton (1993), gambaru representa a filosofia de aprendizagem cultural dos japoneses. É como um elemento do currículo oculto em que professores, pais e a comunidade em geral estimulam as crianças a esforçar-se, persistir, fazer o melhor possível.

No espaço pré-escolar, gambaru pode ser explicitado a partir da teoria de Dewey (1913), da necessidade de respeitar interesses e necessidades infantis. Nas brincadeiras livres, não há a direção do professor. As crianças usam os materiais de acordo com experiências adquiridas no próprio contexto, com o auxílio do professor e seus pares. Aliar o treino, a busca de solução para seus projetos individuais, tendo uma variedade de modelos opcionais, parece ser a orientação adotada pelas escolas públicas japonesas que adotam o brincar em seus projetos pedagógicos.

Segundo Ogawa, a teoria de Dewey, do interesse e do esforço que se manifestam nas brincadeiras, reforça valores provenientes de tempos passados, da era Edo. ${ }^{11}$ Gambaru nas brincadeiras significa usar experiência, interesse e esforço, procurando relações com a coletividade e a sociedade, levando a criança a aprender coisas que faz por si mesma, à semelhança do learning by doing deweyano.

\section{Conclusão}

A nova proposta de educação infantil japonesa em que o brincar se destaca parece encontrar eco nas escolas públicas. Há, entretanto, forte presença de valores culturais antigos,como o espírito coletivo, materializados no sistema de tobam, no grande número de crianças por classe e na preocupação de muitos professores com o desenvolvimento da cooperação e com a inserção da criança no grupo em detrimento da individualidade.

Segundo Lincicome (1993), para pôr em prática as mudanças exigidas pela internacionalização, seria necessário que as futuras gerações fossem encorajadas a desenvolver seu caráter individual (kosei), 
criatividade (sozosei), independência (jiyu), autodisciplina (jiritsu) e responsabilidade pessoal (jiko sekinin), que se encontram na proposta de educação infantil japonesa.

Entretanto, embora o projeto da brincadeira livre ofereça ampla possibilidade para a expressão individual, a sociedade coletivista e competitiva coloca-se como obstáculo à realização desse projeto pedagógico. A pouca participação do poder público na oferta de educação infantil leva a grande maioria (80\%) das crianças a freqüentar instituições particulares, acadêmicas, que não adotam a proposta pedagógica oficial, do brincar como forma de desenvolver a individualidade, a cooperação, a criatividade e a expressão de interesses e necessidades.

Notas

1. Instituições observadas: três jardins-de-infância públicos anexos a universidades nacionais (Tóquio, Shizuoka e Akita), um jardim-de-infância municipal, um jardim-de-infância particular e uma creche particular.

2. Professores de Universidades: Hirohisa Ogawa e Nezu da Gakugei Daigaku; Etsuko Nakamura da Otsuma University e Kaneda Toshiko da Shizuoka Daigaku, responsávaeis pelo curso de formação de professores de educação infantil em nível universitário.

3. Outros dados quantitativos podem ser encontrados em Kishimoto, 1995, pp. 23-44.

4. Versão preliminar, em inglês e japonês, que serve de subsídio para orientação, distribuída pelo Ministério de Educação e Cultura.

5. Objetivos do jardim-de-infância "Education's guideline for Japanese kindergartgen" (1994, p. 2).

6. Conferência proferida na Universidade Gakugei Daidagu, em 14 de fevereiro de 1997.

7. Representante do Ministério de Educação, seção de Educação Infantil, em conferência pronunciada na Universidade Gakugei Daigaku, em 24 de janeiro de 1996.

8. Embora já exista um pequeno contingente de famílias modernas, cujos pais trabalham, em que há divisão de tarefas domésticas, a tradição milenar ainda restringe às mulheres o trabalho doméstico.

9. Durante três meses acompanhei o professor em assessorias prestadas às organizações públicas e privadas em Tóquio, Nagoya, Shizuoka e Akita. 
10. Observações de crianças de 4 a 5 anos, no salão do jardim-de-infância anexo à Universidade Gakuguei Daigaku, preferido para brincadeiras de construção com objetos de grande porte.

11. Manuscritos antigos mostram o cuidado que se dava às crianças pequenas e como o amae, o deixar a criança ser criança, era respeitado.

Toys and games in Japonese infant education: Curriculum proposal for the 1990s

ABSTRACT: Japanese educational politics in the nineties, influenced by globalization and internationalization, are restructuring the official pre-schools. Designed for children of 3 to 5 years, the official preschools define a pedagogical proposal about play, as a way to conduct the child to know his environment, to make himself sociable and creative. Due to the predominance of schools in the field of child education and weak government participation, private play represents a small role in pre-school education.

\section{Bibliografia}

BLINCO, Priscilla Mary Anne. "Persistence and education: A formula for Japan's economic success". Comparative Education $n^{\circ} 2.1993$, vol. 29, pp. 171-183.

DEWEY, John. L'école et l'enfant. Trad. Pidont. L.S. Paris, Neuchatel/ Delachaux S. Niestlé S.A, 1913.

DOI, Takeo. Le Jeu de l'indulgence. Trad. de Saunders, E. Dale. Paris, L' Asiathèque, 1988.

ELLINGTON, Lucien. "Dominant values in Japanese education". In: Comparative Education Review nํㅜㅇ. Agosto de 1990, vol. 34, pp. 405-410.

FACTS AND FIGURES OF JAPAN. Foreign Press Center/Japan, 1995.

FINKELSTEIN, Barbara; IMAMURA, Anne E. e TOBIN Joseph J. (eds.). Transcending stereotypes. Maine, Intercultural Press, 1991.

HENDRY, Joy. Becoming Japanese: The world of the pre-school child. Glasgow, Manchester University Press, 1986.

"Kindergartens and the transition from home to school education". Comparative Education № 1. 1986b, vol. 22, pp. 53-57. 
HINAGO, Taro. What are the caracteristics of the method of early childhood education and care in Japan? In: Early Childhood Education and Care in Japan. Early Childhood Education Association of Japan (org.), Japão, 1979.

HOLLOWAY, Susan D.; FULLER, Bruce et al. "The family's influence on achievement in Japan and the United States". Comparative Education Review no 2. Maio de 1990, vol. 34, pp.196-208.

ISHIZAKA, Kazuo. Educação escolar no Japão. Japão, International Society for Educational Information, Inc., 1991.

JAPAN. Ministry of Education, Science and Culture. "Education's guideline for Japanese kindergarten". 1994, mimeo.

Japanese government policies in education, science and culture. 1994, New Directions in School Education, Fostering Strength for Life (Wagakuni no Bunkyo Shisaku), 1995.

KATO, Shuichi. "The sources of contemporary Japanese culture." In: Essays on Japan from Japan. Public. Relations Dept., Corporate Secretariat Div. Nippon Steel Corporation, Maruzen Co. Ltd. Tokyo, Japão, 1987.

KISHIMOTO, Tizuko Morchida. "A educação infantil no Japão". Cadernos CEDES 37. Centro de Estudos Educação e Sociedade, 1995, pp. 23-44.

KUBO, Ito. "What is the history of kindergartens in Japan?" In: Early childhood education and care in Japan. Early Childhood Education Association of Japan (org.). Japão, 1979, p. 17.

LEWIS, Catherine. "Cooperation and Control in Japanese nursey schools. In: Japanese schooling. Patterns of socialization, equality and political control. Shields, James, J. Jr. (org.). The Pennsylvania State University Press. Pensilvânia, University Park, 1993, pp. 2844.

LINCICOME, Mark. "Focus on internationalization of Japanese education. Nationalism, internationalization and the dilemma of educational reform in Japan". Comparative Education Review no 2. Maio de 1993, vol. 37, pp. 123-151.

MOMBUSHO. Ministry of Education, Sicence, Sports and Culture Government of Japan, 1995. 
MURAYAMA, Sadao; HINAGO, Taro e OKADA, Masatoshi (orgs.). Early childhood education and care in Japan. Japão, Early Childhood Education Association of Japan, 1979.

PEAKS, Lois. Learning to go to school in Japan. Los Angeles, University of California Press, 1991.

SANTOMÉ, Jurjo Torres. O Curriculum oculto. Trad. Anabela Leal de Barros e António Bárbolo Alves. Lisboa, Porto, 1995.

SHIELDS, JR. James J. (org.). Japanese schooling: Patterns of socialization, equality, and political control. Pensilvânia, The Pennsylvania State University Press, 1993.

SINGLETON, John. "Gambaru: A Japanese cultural theory of learning". In: Japanese Schooling. Patterns of socialization, equality and political control. Shields, James, J., Jr. (org.). The Pennsylvanian State University Press. Pensilvânia, University Park, 1993. pp. 8-15.

TERUHISA, Horio. Educational thought and ideology in modern Japan. State Authority and Intellectual Freedom. Tóquio, University of Tokyo Press, 1990.

TOBIN, Joseph Jay; WU, David Y. e DAVIDSON, Dana H. "Class size and student/teachers ratios in the Japanese preschool". Comparative Education Review oㅜ 4. 1987, vol. 31, pp. 533-549.

Preschool in three cultures. Japan, China and the United States. Nova York, Yale University Press, 1989.

TSUMORI, Makoto. "Pioneers who contributed to the childhood education and care in japan will you pick up five and explain about their contributions?" In: Early childhood education and care in Japan. Early Childhood Education Association of Japan (org.). Japão, 1979, p. 21.

WOLLONS, Roberta. "The black forest in a Bamboo Garden: Missionary kindergartens in Japan, 1868-1912". History of Education Quartely № 1. Primavera de 1993, vol. 33, pp.1-35. 